\title{
KNOWLEDGE, ATTITUDE AND PRACTICE OF THE TRAINEE SEAFARERS TO HIV/AIDs AND STIS AT APAPA SEAPORT, LAGOS.
}

*Efunshile AM, ** Oduyebo OO, **Oyibo WA, ** Ogunsola FT ***Fatungase AO, *Osinupebi OA,

*Department of Medical Microbiology \& Parasitology, College of Health Sciences, Olabisi Onabanjo University, PMB 2001 Sagamu ,Ogun State, Nigeria, ** Department of Medical Microbiology \& Parasitology, College of Medicine, University of Lagos, Lagos, Nigeria ***Medical Department, Nigeria Ports Authority, Apapa, Lagos

Correspondence: Dr.A.M Efunshile. E-mail: drefunshile@yahoo.com Tel: 234-1-8034357172

\section{ABSTRACT}

The epidemic of human immunodeficiency virus (HIV) in Nigeria is being fuelled by ignorance and other Sexually Transmitted Infections (STIs). Little is known about HIV-risk related sexual behavior of the Nigerian sailors. This study describes the baseline knowledge, attitude and practice of the trainee sailors to HIV.

Ninety four (83.2\%) of the 113 trainee interviewed consented to participate in voluntary counseling and confidential testing (VCT) programme. Each trainee completed an anonymous self- administered questionnaire and was tested for syphilis, trichomoniasis and $H I V$.

Seventy one (75.5\%) of the respondents were between ages $21-25$ years. Twenty three (25\%) did not believe that having sex with commercial sex workers puts them at high risk of HIV while eighteen $(19.1 \%)$ did not believe that condoms were protective. Only ten (10.6\%) practiced abstinence while three were homosexual. Despite all these, sixty three $(67 \%)$ believed that they were at little or no risk of HIV, prevalence of which was found to be $5.3 \%$ among them. Seventy one $(75.5 \%)$, fifteen (16\%), twenty (21\%) and (20.2\% of respondents believed that genital ulcers, gonorrhea, syphilis and HIV respectively were not sexually transmitted. Trichomoniasis and syphilis were found in two $(2.1 \%)$ and one $(1.1 \%)$ respondents respectively. Female sex $(P=0.002)$ and trichomoniasis $(P=0.017)$ were found to significantly influence HIV infection.

There was a high level of ignorance about HIV and STIs among respondents. This was further highlighted by the high rate of high-risk behaviors. Therefore, sustained educational programs and promotion of condoms are recommended to address this problem.

KEY WORDS:- Trichomoniasis, seafarers, HIV, STIs, syphilis. 


\section{INTRODUCTION}

About 40 million people worldwide are living with HIV, with an estimated 15,000 new infections occurring daily. It is also the leading cause of death in sub-Saharan Africa ${ }^{1,2}$. Sub-Saharan Africa accounts for almost $70 \%$ of the global total of HIV-positive

people and $83 \%$ of cumulative AIDS deaths ${ }^{3}$. Nigeria with a prevalence of $5.0 \%$ accounts for over 3 million

people living with HIV, where it is estimated to be spreading at the rate of one person per minute, threatening Africa's most populous nation ${ }^{4}$

It has been shown conclusively that acquiring Sexually Transmitted Infections (STIs) increases the risk of acquiring HIV. This is not only because they share the same routes of transmission but STIs actually increase the efficacy of acquisition and transmission of HIV by 1.5 - to 7 - fold ${ }^{2}$. Therefore commercial sex workers (CSWs) and men that have sex with men are at a high risk ${ }^{5,6}$.

Sexual transmission of HIV is also fuelled by mobility, with migrant workers spending long periods of time away from home and frequently visiting CSWs, then returning home to infect their spouses. HIV is therefore spreading among traveling salesmen, soldiers, long distance truck drivers and sailors ${ }^{6 .}$

A recent study among Nigerian Naval personnel showed that most of them believed that AIDS exists and over $50 \%$ of them also felt that a cure was available in Nigeria ${ }^{7}$. The study also showed that $40 \%$ of those who had been with CSWs had not used a condom during the last encounter. In this study we targeted trainee seafarers at the Apapa seaport to determine their baseline knowledge, attitude and practices as it relates to HIV and STIs and to determine the prevalence of these infections. Follow up studies are planned to determine the effect of the profession on their attitudes towards HIV and practice of safer sex.

\section{MATERIALS AND METHODS}

\section{Study population.}

The study was performed over a period of two months on trainee seafarers that were less than one year in training at the Nigerian Ports Authority, Apapa, Lagos. The seafarers were 150 in all. One hundred and thirteen $(75.3 \%)$ of them were available for counseling out of which $94(62.7 \%)$ agreed to participate. Written informed consent was obtained from each participant after counseling on safe sex practices. Participation in the study was voluntary and confidential.

\section{Knowledge, attitude and practices of participants regarding HIV and safer sex.}

A self-administered questionnaire was given to the participants to evaluate their knowledge, attitude and practices toward HIV and STIs. 


\section{Specimen collection and transportation}

For HIV and syphilis testing, $5 \mathrm{mls}$ of blood was collected from each participant into sterile, plain screw cap plastic tubes and transported to the laboratory on ice and the serum was separated within an hour and stored at $-70 \% \mathrm{c}$. For Trichomonas vaginalis microscopy, first void urine was collected from male participants into sterile universal containers while selfadministerd sterile swab sticks were used by the female participants to collect vaginal secretions. These were transported to the laboratory immediately.

\section{HIV testing}

The GENIE Il HIV-1/HIV-2 kit (Bio-rad, 3 Bd Raymond Poincare 92430 Marnes La Coquette. France) was used for qualitative detection of HIV antibodies in participant's sera.

All tests were controlled with manufacturer's provided positive and negative controls and interpreted in line with manufacturers manual.

All samples were further tested by quantitative EIA standard method using GENSCREEN ${ }^{(a)}$ PLUS HIV Ag-Ab for HIV 1 \& 2 (Bio-rad, 3 Bd Raymond Poincare 92430 Marnes La Coquette, France), a fourth generation kit. The presence of detectable HIV antibodies or antigen was determined by comparing the absorbance measured for each sample to the calculated cut-off value in line with manufacturer's instructions.

\section{Syphilis testing.}

Serum from each participant was tested for antibodies to syphilis with Rapid Plasma Reagin kit (Becton and Dickinson and co. 7, loveton circle Sparks, Maryland 21152 USA) in line with manufacturer's instructions. All reactive samples were further tested by specific Treponemal pallidum heamagglutination assay (TPHA) for confirmation. Samples reactive by TPHA were considered positive for T. pallidum.

\section{T.vaginalis testing}

Sediment from centrifuged urine from males and the wet preparations of vaginal secretion from females were examined microscopically within two hours of collection. Demonstration of ovoid trophozoites with the typical jerky motility was considered diagnostic of inalis. T.vagimitis.

\section{Data analysis}

The completed questionnaires were checked for completeness and open-ended questions were coded. The data was analyzed with Epi-Info software package, version 6.0. Chi-square analysis was used to determine association between variables. $P$-values of $<0.05$ was taken as significant.

\section{RESULTS}

\section{Socio demographic-data.}


The ages of the 94 respondents ranged from 15 to 40 years with the largest percentage ( $75.5 \%$ ) belonging to the $21-25$ years age group, (table i). Only one respond Seventy one $(75.5 \%)$ were males, while the rest were females. Eighty seven (92.6\%) had secondary school education while the rest had higher diploma. Most were Christians with $51 \%$ being Pentecostals and $13.8 \%$ being Catholics. Only $6.4 \%$ of them were Moslems.

he most common tribes were the Hausa/Fulani $(25.5 \%)$, followed by the [bos $(22.3 \%)$ and the Yorubas $(8.5 \%)$. The rest were from other tribes.

sex with more than two persons in the last 3 months, (table ii). Fifteen (15.9\%) never used a condom when they had sex,

Table i: HIV prevalence in different age groups

\begin{tabular}{|l|l|l|l|l|}
\hline AGE & HIV & HIV & TOTAL NUMBER OF & $\%$ \\
GROUP & POSITIVE & NEGATIVE & RESPONDENTS & POSITIVE \\
\hline $15-20$ & O & 3 & 3 & 0 \\
\hline $21-25$ & 4 & 67 & 71 & 5.6 \\
\hline $26-30$ & 1 & 18 & 19 & 5.3 \\
\hline $31-40$ & 0 & 1 & 1 & 0 \\
\hline Total & 5 & 89 & 94 & 5.3 \\
\hline
\end{tabular}

Table ii: Number of sex partners in previous 3 months and HIV prevalence.

\begin{tabular}{|l|l|l|l|l|}
\hline SEX PARTNERS & HIV & HIV & TOTAL NUMBER & $\%$ \\
& POSITIVE & NEGATIVE & OF RESPONDENTS & POSITIVE \\
\hline O & 0 & 29 & 29 & 0 \\
\hline 1 & 2 & 44 & 46 & 4.3 \\
\hline 2 & 2 & 7 & 9 & 22 \\
\hline Tor more & 1 & 9 & 10 & 10 \\
\hline
\end{tabular}

$37(39.4 \%)$ sometimes used condom while $33(35 \%)$ always used condoms, (table iii).

Eight respondents had sex with CSWs while another eight had sex with casual acquaintance. The rest had regular partners. Three $(3.2 \%)$ of the respondents were involved in homosexual activities. 
Table iii: Use of condom and HIV prevalence

\begin{tabular}{|c|c|c|c|c|}
\hline $\begin{array}{l}\text { CONDOM } \\
\text { USE. }\end{array}$ & $\begin{array}{l}\text { HIV } \\
\text { POSITIVE }\end{array}$ & $\begin{array}{l}\text { HIV } \\
\text { NEGATIVE }\end{array}$ & $\begin{array}{l}\text { TOTAL NUMBER } \\
\text { OF RESPONDENTS }\end{array}$ & $\begin{array}{l}\% \\
\text { POSITIVE }\end{array}$ \\
\hline ABSTINENCE & 0 & 10 & 10 & 0 \\
\hline NON USE. & 2 & 13 & 15 & 13 \\
\hline SOMETIMES & 2 & 35 & 37 & 5.4 \\
\hline ALWAYS & 1 & 31 & 32 & 3.1 \\
\hline Total & 5 & 89 & 94 & 5.3 \\
\hline
\end{tabular}

\section{HIV/STDs knowledge and attitude.}

Eighty five $(90 \%)$ of the respondents had heard of HIV/AIDs but fourteen (14.9\%) did not know how it is transmitted. Twenty seven $(28.2 \%)$ believed that it could not be transmitted from mother-to-child. Some also believed that it could not be transmitted by blood transfusion (9.6\%) and contaminated needles (25.5\%). Some believed that HIV couldn't be prevented by abstinence $(12.8 \%)$, condom (19.1\%), mutual fidelity $(16.0 \%)$ and avoiding sex with CSWs (25.5\%). Forty (42.6\%) respondents knew someone who was living with or had died of AIDS, while 24 (25.5\%) had a close relative infected with HIV. About $67 \%$ believed that they had little or no risk of HIV. Only six (6.4\%) felt they were at high risk and three of these believed it was because they were very sexually active while the other three believed it would be through the barber. Seventy five $(79.8 \%)$ respondents had never been tested for HIV. Twenty three $(24.5 \%)$ were not aware that HIV could be contracted through sex.

\section{HIV/STIs prevalence.}

Five respondents tested positive for HIV by rapid EIA method, while 13 respondents tested positive for HIV by quantitative EIA method including the five that were positive by rapid EIA. The five that tested positive by both methods were regarded as 'HIV POSITIVE', four of who were female. The eight that were positive by quantitative EIA alone were regarded as 'discordant' and were advised to have a re-bleed after six months. Two (2.2\%) of the respondents had trichomoniasis while only one $(1.1 \%)$ had syphilis.

The two respondents with $T$. vaginalis infection were also HIV positive, but the single respondent positive for T.pallidum infection was not positive for HIV or T.vaginalis.

\section{DISCUSSION}

The respondents generally had a good knowledge of routes of HIV infection with $90 \%$ being well informed, However, some, still harbor misconceptions such as the belief that HIV/AIDs is not transmitted by sexual intercourse and that it cannot be prevented by abstinence, condom, mutual fidelity and avoiding sex with CSWWs. Despite the 
relatively good knowledge about sexual transmission of HIV, only $32(34 \%)$ of the respondents used condom always. Similar findings were noted during the 2003 national survey ${ }^{5}$ which showed an awareness of over $88 \%$ with only $19 \%$ having a complete knowledge of HIV transmission. The percentage of respondents $(67 \%)$ who believed that they had little or no chance of contracting HIV is similar to the latest national figures $(72 \%)$ in the civilian population ${ }^{5}$. This low perception of risk is probably influenced by the widespread denial of the existence of HIV in the country. ${ }^{8}$ It has been found that fewer women encourage the use condom during risky sex than men (32\% and $51 \%$ respectively) ${ }^{5}$, this may explain why female sex is more associated with HIV infection in this study $(\mathrm{p}=0.002)$.

The prevalence of HIV in this potentially high risk group $(5.3 \%)$ is a bit higher than the national figure of $5.0 \%{ }^{5}$. This is not surprising since many engage in risky sexual practices such as having multiple sexual partners, homosexuality, visiting CSWs and poor usage of condom.

The pravelence of trichomoniasis in Nigeria vary widely and it depends on the population examined. While Konje et al found a prevalence of $2.52 \%$ among adult women from the cytology clinic of the University College Hospital, Ibadan 9, Anorlu et al, found a prevalence of $74.5 \%$ in patients with vaginal discharge in Lagos ${ }^{10}$. Our result $(2.1 \%)$ is close to that of Konje et al.

The prevalence of syphilis is generally low in Nigeria. Dada et al. found syphilis prevalent of $4 \%$ among female sex workers in
Lagos 11 while Obiechina et al, found a prevalence of $2.1 \%$ among the HIV patients who attended the skin clinic of the University of Nigeria, Teaching Hospital, Enugu ${ }^{12}$. The prevalence found in this study $(1.1 \%)$ is even much lower than the two. This may be due to the fact that since more than half a century ago when Mahoney et al successfully treated the first four cases of syphilis with penicillin, it remains the drug of choice ${ }^{13}$. Also, most antimicrobials used to treat other STIs have been found to eradicate incubating syphilis ${ }^{14}$.

The association of trichomoniasis with HIV in this study ( $p=0.017)$ makes it an important disease that requires regular surveillance and quick intervention. Emphasis must therefore be placed on primary prevention of STIs and not specifically limited to HIV but addressing the entire problem of STIs. Interventions targeted at the seafarers must also include education on safer sex.

\section{REFERENCES}

1. The Joint United Nations Programme on HIV/AIDS, Report on the global HIV/AIDS epidemic: 2002.

2. Gayle HD, Hill GL. 2001. Global Impact of HIV/AIDs. Clin Microbiol Reviews; 14(2): $327-335$.

3. The Joint United Nations Programme on HIV/AIDS, Report on the global HIV/AIDS epidemic: Geneva, Switzerland, 1999. 
4. Federal Ministry of Health of Nigeria. National HIV/AIDS, and Reproductive Health Survey, 2003

5. The Joint United Nations Programme on HIV/AIDS, AIDS epidemic update, December 2003.

6. National AIDS Control Organization, India, HIV estimates in India, www.naco.nic.in/indiansene/esthiv.htm

7. Nwokoji UA, Ajuwon AJ. 2004. Knowledge about AIDS/HIV risk related sexual behavior among Nigerian naval personnel. BMC public health; $4: 23$

8. Alubo O. 2002. Breaking the wall of silence: AIDS policy and politics in Nigeria. Inter J Health Serv; 32:551-556.

9. Konje JC, Otolorin EO, Ogunniyi JO, Obisesan KA, Ladipo OA. The prevalence of Gardnerella vaginalis, T. vaginalis and Candida albicans in the cytology clinic at Ibadan, Nigeria. Afr J Med Med Sci. 1991; 20: 29-34
10. Anorlu RI, Fagbenro Beyioku AF, Fagorala T, Abudu OO, Galadanci HS.

Prevalence of trichomonas vaginalis in patients with vaginal discharge in Lagos, Nigeria. Niger Postgrad Med J. 2001; 8:183-186.

11. Dada A.J, Ajayi A.O, Dilamondstone L, Quinn T.C, Blattner W.A, Biggar R.J.(1998). A serosurvey of Haemophilus ducreyi, syphilis,

12. and herpes simplex virus type 2 and their association with human immunodeficiency virus among female sex workers in Lagos, Nigeria. Sex Transm Dis; 25:237-242.

13. Obiechina J.A, Nwosu O B, Okafor C l, Ikpeze OC. Knowledge, awareness and perception of sexually transmitted diseases (STDs) among antenatal patients at Nnewi, Nigeria. $J$ Obstet Gynaecol. 2001; 21:292-294.

14. Mahoney J.F, Arnold R.C, Harris A.D.(1943). Penicillin treatment of early syphilis. Am J Public Hedth. 33:13871391.

G.Thomas Strickland. Hunter's Troppical medicine and emerging infectious diseases. $8^{\text {th }} \mathrm{ed}, \operatorname{pg} 359$, 2000 . 